\title{
Equilibrium Model of Discrete Dynamic Supply Chain Network with Random Demand and Advertisement Strategy
}

\author{
Guitao Zhang, ${ }^{1}$ Qingmei Sui, ${ }^{2}$ Jinsong Hu, ${ }^{1}$ Yongguang Zhong, ${ }^{1}$ and Hao Sun \\ ${ }^{1}$ School of Management Science and Engineering, Qingdao University, Qingdao 266071, China \\ ${ }^{2}$ School of Control Science and Engineering, Shandong University, Jinan 250062, China \\ Correspondence should be addressed to Jinsong Hu; hujinsong@qdu.edu.cn
}

Received 25 April 2014; Accepted 17 July 2014; Published 26 August 2014

Academic Editor: Ming Gao

Copyright (c) 2014 Guitao Zhang et al. This is an open access article distributed under the Creative Commons Attribution License, which permits unrestricted use, distribution, and reproduction in any medium, provided the original work is properly cited.

\begin{abstract}
The advertisement can increase the consumers demand; therefore it is one of the most important marketing strategies in the operations management of enterprises. This paper aims to analyze the impact of advertising investment on a discrete dynamic supply chain network which consists of suppliers, manufactures, retailers, and demand markets associated at different tiers under random demand. The impact of advertising investment will last several planning periods besides the current period due to delay effect. Based on noncooperative game theory, variational inequality, and Lagrange dual theory, the optimal economic behaviors of the suppliers, the manufactures, the retailers, and the consumers in the demand markets are modeled. In turn, the supply chain network equilibrium model is proposed and computed by modified project contraction algorithm with fixed step. The effectiveness of the model is illustrated by numerical examples, and managerial insights are obtained through the analysis of advertising investment in multiple periods and advertising delay effect among different periods.
\end{abstract}

\section{Introduction}

In the 1980s, the interest in supply chain and supply chain management increased tremendously. Supply chain management, which incorporates the raw materials supplying, production and distribution in the demand markets in the end [1], is a hot topic in the academic world as well as the business community. There is abundance of research available on the supply chain management. We refer the readers to the work of [2] to achieve a comprehensive review on the supply chain topic.

These researches mainly focus on the stringy supply chain or a single manufacturer. In fact, the supply chain is a network which consists of suppliers, manufacturers, retailers, and demand markets [3]. Thus, there is limited contribution in the previous literature that addresses the competition between the players with the same function, such as various manufacturers making the homogenous products, and the complexity resulting from so many actors in the supply chain network system. By the concept of equilibrium, Nagurney et al. [4] explore in the general supply chain network setting.
Other researchers expand the work of Nagurney et al. [4]. In particular, Dong et al. [5] study the supply chain network equilibrium with stochastic market demand which need get the density function or distribution function of random demand from history data.

In practice, demand uncertainties arise from the complexity and the evolvement over time of supply chain network which is actually a dynamic system [6]. The dynamics of our world results in the changing of network construct; thus we can discrete the fixed time into several planning periods, and in one planning period, the parameters in the network are stable, whereas in different periods, there are some changes such as the raw materials price fluctuation or the demand parameter transformation in the markets. In this paper, we model the discrete dynamic supply chain network equilibrium.

Moreover, in order to promote the product, firms usually use some marketing strategies such as advertising. Advertising is a common marketing activity and is widely used by enterprises. Local advertising, which focuses on the local market, is mainly accomplished by the cooperation between 
manufacturer and retailer [7]. Since the retailer is closer and familiar with the consumers, she may have an efficient local advertising channel, and the manufacturer may provide the retailer a part of money for local advertising purpose. Warner Brothers, a maker of corsets, issued the first co-op agreement in 1903 [7]. From then on, the use of co-op advertising spreads to other industrials such as grocery stores and fashion, and the automobile is the most common user of cooperative advertising today.

The advocating of advertisement could make consumers learn about the characters and related knowledge of the products provided by manufacturers and retailers, so more consumers will purchase this product, which result in the total market share increasing. If we consider the advertisement strategy in a dynamic decision context, then the relationship among different periods must be taken into consideration. For example, the advertising investment in the current period also has some effects in the next periods, and this effect will reduce over time. This paper incorporates the co-op advertising investment strategy in discrete dynamic decision-making environment, and the investment will be shared by manufacturers and retailers; the sharing ratio is determined by negotiation between the two tire players. As we see in the numerical examples, it is interesting to note that the value of ratio does not impact the equilibrium results. Since the advertising strategy is an option that is underutilized, enterprises are unsure about the economic performance of advertising investment.

To mitigate the ambiguity about advertising investment for decision makers, in the paper, we model the role of advertising investment in a supply chain network over time. Similar to literatures of supply chain network, we assume the players in the same tier such as all manufacturers compete in a noncooperative fashion and the players in different tiers such as manufacturers and retailers must cooperate in order to agree with each other in transaction price and amount. In the network, decision makers including manufacturers and retailers need to decide on the appreciation level of advertisement investment so that they sell more products to demand markets to maximize the profit. To simplify problem studied, we will illustrate this point through numerical examples and consider the investment levels as a constant instead of a decision variable.

This paper is organized as follows. Section 2 gives assumptions and notations. In Section 3, we model the optimal behaviors of various players in supply chain network. In turn, we establish the equilibrium model of the whole network. Section 4 provides solution algorithm for the model established, and in Section 5, we illustrate the effective and managerial insights by numerical examples. Finally, in Section 6, we conclude the paper.

\section{Literature Review}

Over the past decades, in the context of supply chain, advertising strategy has grown up and becomes an important research topic in operations research and management area. Cooperative advertising generally has five different meanings [23]. In our research, we employ the first one that is vertical cooperative advertising which is also the most common comprehension. The manufacturers offer to share a certain percentage of the downstream retailers' advertising expenditures [24]. We also refer the readers to the work of [23] and the literature therein to get a general review about advertising. Based on the time dependence of parameters and decision variables, Lei et al. [25] and Xiao et al. [26] propose various multiperiod models to illustrate the impact of advertising investment on supply chain, whereas Chen [27], He et al. [28], Tsao and Sheen [29], and Xiao et al. [26] pick up the topic of stochastic environment associated with advertisement. Using game theoretic methods and from two main parts, simple marketing channels and a more complex structure, Jogensen and Zaccour [30] survey the literature on cooperative advertising in marketing channels (supply chains). Considering corporate social responsibility, Zhang et al. [31] examine the effectiveness of an advertising initiative in a leader-follower supply chain with one manufacturer and one retailer. Lambertini [32] characterizes an optimal twopart tariff specified as a linear function of the upstream firm's advertising effort, performing this task both in the static and in the dynamic games. It is necessary to point out that these researches mainly pay attention to the simple supply chain or a single firm but do not consider the complexity and the mutual impacts among firms in the supply chain network.

Besides the research of Dong et al. [5], Nagurney et al. [8], Nagurney and Toyasaki [9], Wu et al. [10], Hammond and Beullens [11], Yang et al. [12], Masoumi et al. [13], and Yu and Nagurney [15], Toyasaki et al. [16] study the supply chain network equilibrium problems from various perspectives and different supply chain networks. Qiang et al. [14] establish a closed-loop supply chain network model considering the competition, distribution channel investment, and demand uncertainties. The literatures mentioned above deal with static supply chain or static supply chain network equilibrium problems.

Recently, a few authors explore supply chain network equilibrium problems in dynamic setting. For example, Cruz and Wakolbinger [17] develop a framework for the analysis of the optimal levels of corporate social responsibility (CSR) activities in a multiperiod supply chain network consisting of manufacturers, retailers, and consumers and describe the problem of carbon emissions. Daniele [18] considers a supply chain network model with three tiers of decision makers (manufacturers, retailers, and consumers) in the case when prices and shipments are evolving on time. Cruz and Liu [19] analyze the effects of levels of social relationship on a multiperiod supply chain network with multiple decision makers associated at different tiers. Hamdouch [20] establishes a three-tier equilibrium model with capacity constraints and retailers' purchase strategy from a multiperiod perspective. Liu and Cruz [21] provide an analytical framework to investigate how financial risks affect the values of interconnected supply chain firms from a network perspective and how financial risks affect the supply chain firms' profitability and the cash and credit transactions. Feng et al. [22] develop a closed-loop supply chain super network model in which 
TABLE 1: Literature sources for network equilibrium.

\begin{tabular}{lcccc}
\hline No. & Authors & Static/dynamic & Demand characteristic & Considering factor \\
\hline 1 & Nagurney et al. (2002) [4] & Static & Deterministic & No \\
2 & Dong et al. (2004) [5] & Static & Random uncertainty & No \\
3 & Nagurney et al. (2005) [8] & Static & Random uncertainty & B2B transaction, risk \\
4 & Nagurney and Toyasaki (2005) [9] & Static & Deterministic & No \\
5 & Wu et al. (2006) [10] & Static & Deterministic & Collection \\
6 & Hammond and Beullens (2007) [11] & Static & Collection \\
7 & Yang et al. (2009) [12] & Static & Deterministic & No \\
8 & Masoumi et al. (2012) [13] & Static & Deterministic & Channel investment \\
9 & Qiang et al. (2013) [14] & Static & Random uncertainty & No \\
10 & Yu and Nagurney (2013) [15] & Static & Deterministic & No \\
11 & Toyasaki et al. (2014) [16] & Static & Deterministic & Corporate social responsibility \\
12 & Cruz and Wakolbinger (2008) [17] & Discrete dynamic & Deterministic & No \\
13 & Daniele (2010) [18] & Continuous dynamic & Deterministic & Social relationship \\
14 & Cruz and Liu (2011) [19] & Discrete dynamic & Deterministic & Purchase strategy \\
15 & Hamdouch (2011) [20] & Discrete dynamic & Deterministic & Corporate financial risks, trade credits \\
16 & Liu and Cruz (2012) [21] & Discrete dynamic & Deterministic & Channel investment \\
17 & Feng et al. (2014) [22] & Continuous dynamic & Deterministic &
\end{tabular}

the demand is seasonal and the manufacturers invest the reverse distribution channel for advocating consumers to return more end-of-life products.

The metamorphosis of supply chain network equilibrium literature of recent years is reviewed in Table 1. From Table 1 and literature survey, it is clearly evident that there is no research on discrete dynamic supply chain network equilibrium with advertising strategy and demand uncertainties.

In this paper, our model captures the planning process and the change of costs and demands and highlights the performance of advertising with delay effect, and moreover, this model expresses the uncertainties popularly existing in practice.

\section{Model Assumptions and Notations}

3.1. Model Assumptions. We consider a supply chain network consisting of $S$ suppliers, $M$ manufacturers, $N$ retailers, and $K$ demand markets and let $s$ denote a typical supplier, $m$ a typical manufacturer, $n$ a typical retailer, and $k$ a typical demand market; a retailer is matching a demand market; that is, one retailer only deals with the demand of one demand market. All actors in the same tire compete in a noncooperative fashion. Figure 1 illustrates the simple supply chain network with 2 suppliers, 2 manufacturers, 2 retailers, and 2 demand markets in 2 periods. $s_{1}(1)$ denotes the first supplier in the first period, and $s_{2}(1)$ denotes the second supplier in the first period; the other notations can be explained in the same way. The real lines between two adjacent tiers denote the related transaction activities, and the dash lines between 2 periods denote inventory transferring from the former period to the latter period.

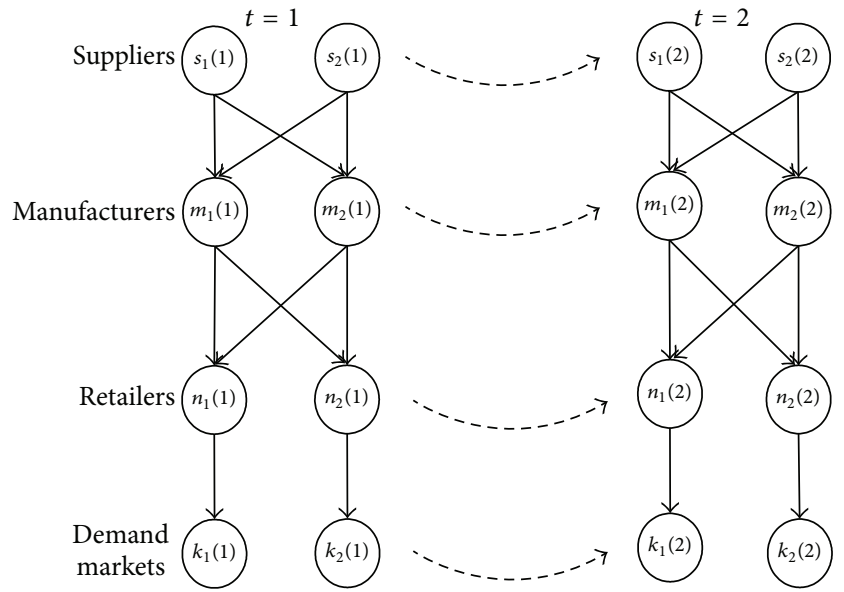

FIgURE 1: An illustration of 2-period supply chain network.

In order to explicate the problem studied, we give the following assumptions:

(1) All vectors are column vectors;

(2) The equilibrium solution or the optimal value of a decision variable is denoted by "*”;

(3) The advertising investment is a constant and shared between the pairs of manufacturer and retailer;

(4) All cost functions and transaction functions are continuous convex and differentiable;

(5) All players in the network are risk neutral. 
TABLE 2: Basic parameters in the closed-loop supply chain network figure.

\begin{tabular}{ll}
\hline Notation & Definition \\
\hline$\beta^{r}$ & Raw material conversion rate \\
$t$ & A typical period, $t=1,2, \ldots, T$ \\
$s$ & A typical supplier, $s=1,2, \ldots, S$ \\
$m$ & A typical manufacturer, $m=1,2, \ldots, M$ \\
$n$ & A typical retailer, $n=1,2, \ldots, N$ \\
$k$ & A typical demand market, $k=1,2, \ldots, K$ \\
$\lambda_{n}^{-}(>0)$ & The unit cost of product shortage of retailer $n$ \\
$\lambda_{n}^{+}(>0)$ & The unit cost of product excess of retailer $n$ \\
$\phi_{m n}$ & Advertising investment ratio shared by manufacturer $m$ \\
\hline
\end{tabular}

TABLE 3: Transactions and production variables associated with various players in the network.

\begin{tabular}{ll}
\hline Notation & Definition \\
\hline$q_{s m}^{r}(t)$ & $\begin{array}{l}\text { The raw material transaction volume from supplier } s \text { to manufacturer } m \text { at period } t \text {; group all of } \\
\text { these variables into a column vector } Q^{1} \in R_{+}^{S M T}\end{array}$ \\
$q_{s}^{r}(t)$ & $\begin{array}{l}\text { The total raw material volume provided by supplier } s \text { to all manufacturers at period } t \text {; group all of } \\
\text { these variables into a column vector } q_{1}^{r} \in R_{+}^{S T}\end{array}$ \\
& The total raw material volume of manufacturer $m$ used to produce at period $t$; group all of these \\
$q_{m}^{r}(t)$ & variables into a column vector $q^{r} \in R_{+}^{M T}$ \\
& The product transaction volume from manufacturer $m$ to retailer $n$ at period $t$; group all of these \\
$q_{m n}(t)$ & variables into a column vector $Q^{2} \in R_{+}^{M N T}$ \\
$\rho_{m n}(t)$ & The transaction price charged by manufacturer $m$ for retailer $n$ at period $t$ \\
$\rho_{n}(t)$ & Price charged by retailer $n$ to the product in his outlet for corresponding demand market $k$ at period $t$ \\
$\phi_{n}\left(x ; \rho_{n}(t)\right)$ & The density function of random variable $x$ \\
$\Phi_{n}\left(x ; \rho_{n}(t)\right)$ & The distribution function of random variable $x$ \\
$I_{m}(t)$ & The inventory of manufacturer $m$ at period $t$; group all of $I_{m}(t)$ into a column vector $I \in R_{+}^{M T}$
\end{tabular}

3.2. Variables and Notations. The variables and notations are defined as in Tables 2 and 3 , and the production functions and transaction functions are defined as in Table 4.

\section{Discrete Dynamic Supply Chain Network Equilibrium Model}

4.1. The Optimal Behavior and Equilibrium Condition of Suppliers. In each period, supplier $s$ provides raw material to various manufacturers at the beginning of every period and makes decision associated with trade and production volume of raw material to maximize the profit in the entire planning horizon. Using the notations defined previously, the profit maximum criterion for supplier $s$ can be described as

$$
\begin{aligned}
\pi_{s}=\max \{ & \sum_{t=1}^{T} \sum_{m=1}^{M} \rho_{s m}^{r}(t) q_{s m}^{r}(t) \\
& \left.-\sum_{t=1}^{T} \sum_{m=1}^{M} c_{s m}^{r}(t)-\sum_{t=1}^{T} f_{s}^{r}\left(q_{1}^{r}(t)\right)\right\}, \\
\text { s.t. } \quad & \sum_{m=1}^{M} q_{s m}^{r}(t) \leq q_{s}^{r}(t), \\
\left(q_{s m}^{r}(t),\right. & \left.q_{s}^{r}(t)\right) \in R_{+}^{(M+1) T}, \quad \forall s .
\end{aligned}
$$

Equation (2) expresses that production output of raw material cannot be lower than total volume of the raw material transaction between the supplier $s$ and the various manufacturers.

In this paper, we assume that all the suppliers compete in a noncooperative fashion. Therefore, we can simultaneously express the equilibrium condition of the suppliers as the variational inequality, determining $\left(q_{1}^{r *}, Q^{1 *}, \eta_{s}^{*}\right) \in \Omega^{S}$, such that

$$
\begin{gathered}
\sum_{t=1}^{T} \sum_{s=1}^{S}\left[\frac{\partial f_{s}^{r}\left(q_{s}^{r *}(t)\right)}{\partial q_{s}^{r}(t)}-\eta_{s}^{*}(t)\right] \times\left[q_{s}^{r}(t)-q_{s}^{r *}(t)\right] \\
+\sum_{t=1}^{T} \sum_{s=1}^{S} \sum_{m=1}^{M}\left[\frac{\partial c_{s m}^{r *}(t)}{\partial q_{s m}^{r}(t)}-\rho_{s m}^{r *}(t)+\eta_{s}^{*}(t)\right] \\
\times\left[q_{s m}^{r}(t)-q_{s m}^{r *}(t)\right] \\
+\sum_{t=1}^{T} \sum_{s=1}^{S}\left[\begin{array}{l}
\left.q_{s}^{r *}(t)-\sum_{m=1}^{M} q_{s m}^{r *}(t)\right] \\
\times\left[\eta_{s}(t)-\eta_{s}^{*}(t)\right] \geq 0 \\
\forall\left(q_{1}^{r}, Q^{1}, \eta_{s}\right) \in \Omega^{S}
\end{array}\right.
\end{gathered}
$$

where $\Omega^{S}=R_{+}^{S T+S M T+S T}$. 
TABLE 4: Functions associated with various players in the network.

\begin{tabular}{ll}
\hline Notations & Definition \\
\hline$f_{s}^{r}(t)=f_{s}^{r}\left(q_{1}^{r}(t)\right)$ & The raw material production cost function of supplier $s$ at period $t$ \\
$c_{s m}^{r}(t)=c_{s m}^{r}\left(q_{s m}^{r}(t)\right)$ & The transaction cost function between supplier $s$ and manufacturer $m$ at period $t$ \\
$f_{m}^{M}(t)=f_{m}^{M}\left(\beta_{r}, q^{r}(t)\right)$ & The production cost function using raw materials of manufacturer $m$ at period $t$ \\
$c_{n}(t)$ & The exhibition and disposal cost at retailer $n$ at period $t$ \\
$c_{m n}(t)=c_{m n}\left(q_{m n}(t)\right)$ & The transaction cost function between manufacturer $m$ and retailer $n$ at period $t$ \\
$H_{m}(t)=H_{m}\left(I_{m}(t)\right)$ & The inventory cost function at manufacturer $m$ \\
$f_{t}^{t+i}$ & The delay effect factor of advertising investment at period $t$ on the period $t+i$ \\
$d_{k}\left(\rho_{k}(t), I_{A}^{m n}(t)\right)$ & The demand function associated with demand market $k$ \\
\hline
\end{tabular}

In (4), $\eta_{s}(t)$ is the Lagrange multiplier corresponding to constraint (2) and $\eta_{s} \in R_{+}^{S T}$ is the column vector with the elements of $\eta_{s}(t)$.

Based on the equivalence of variational inequality and complement problem, from the second term of (4), we get

$$
\rho_{s m}^{r *}(t)=\frac{\partial c_{s m}^{r *}(t)}{\partial q_{s m}^{r}(t)}+\eta_{s}^{*}(t) .
$$

From the 1 st term of (4), in the equilibrium state, $\eta_{s}^{*}(t)=$ $\partial f_{s}^{r}\left(q_{s}^{r *}(t)\right) / \partial q_{s}^{r}(t)$; that is, $\eta_{s}^{*}(t)$ is equal to the marginal production cost. Therefore, (5) shows that the transaction price between suppliers and manufacturers is equal to the sum of marginal transaction cost and marginal production cost.

4.2. The Optimal Behavior and Equilibrium Condition of Manufacturers. The manufacturers purchase the raw materials from various suppliers to make products and sell the new products to retailers at every period and in the same time manage inventory between periods according to the market conditions. The manufacturer $m$ seeks to maximize her profit that can be described as follows:

$$
\begin{gathered}
\pi_{m}=\max \left\{\sum_{t=1}^{T} \sum_{n=1}^{N} \rho_{m n}(t) q_{m n}(t)-\sum_{t=1}^{T} \sum_{s=1}^{S} \rho_{s m}(t) q_{s m}(t)\right. \\
\quad-\sum_{t=1}^{T} f_{m}^{M}(t)-\sum_{t=1}^{T} \sum_{n=1}^{N} c_{m n}(t)-\sum_{t=1}^{T} H_{m}(t) \\
\left.\quad-\sum_{t=1}^{T} \sum_{n=1}^{N} \phi_{m n} I_{A}^{m n}(t) q_{m n}(t)\right\}, \\
\text { s.t. } \quad I_{m}(t-1)+\beta_{r} q_{m}^{r}(t)=I_{m}(t)+\sum_{n=1}^{N} q_{m n}(t), \\
q_{m}^{r}(t) \leq \sum_{s=1}^{S} q_{s m}^{r}(t) .
\end{gathered}
$$

Equation (7) expresses the flow conservation; the sum of production volume from raw materials in $t$ period and the transferring inventory from $t-1$ period is equal to the sum of the transaction volume with all retailers and the transferring inventory to next period, and assume the corresponding Lagrange multiplier is $\lambda_{m}(t) ; \lambda \in R^{M T}$ is the column vector with the elements of $\lambda_{m}(t)$. Equation (8) shows that the raw materials amount obtained in manufacturer $m$ is not higher than that various suppliers sent to her; similarly, assume the corresponding Lagrange multiplier is $\gamma_{m}(t)$ and $\gamma \in R_{+}^{M T}$ is the column vector with the elements of $\gamma_{m}(t)$.

The profit maximum object of all manufacturers can be described as a variational inequality, determining $\left(q^{r *}, Q^{1 *}, Q^{2 *}, I^{*}, \gamma^{*}, \lambda^{*}\right) \in \Omega^{M}$, such that

$$
\begin{aligned}
& \sum_{t=1}^{T} \sum_{m=1}^{M}\left[\frac{\partial f_{m}^{M *}(t)}{\partial q_{m}^{r}(t)}-\beta_{r} \lambda_{m}^{*}(t)+\gamma_{m}^{*}(t)\right] \times\left[q_{m}^{r}(t)-q_{m}^{r *}(t)\right] \\
& +\sum_{t=1}^{T} \sum_{m=1}^{M} \sum_{s=1}^{S}\left[\rho_{s m}^{*}(t)-\gamma_{m}^{*}(t)\right] \times\left[q_{s m}(t)-q_{s m}^{*}(t)\right] \\
& +\sum_{t=1}^{T} \sum_{m=1}^{M} \sum_{n=1}^{N}\left[\frac{\partial c_{m n}^{*}(t)}{\partial q_{m n}(t)}+\lambda_{m}^{*}(t)-\rho_{m n}^{*}(t)+\phi_{m n} I_{A}^{m n}(t)\right] \\
& \quad \times\left[q_{m n}(t)-q_{m n}^{*}(t)\right] \\
& +\sum_{t=1}^{T} \sum_{m=1}^{M}\left[\frac{\partial H_{m}^{*}(t)}{\partial I_{m}(t)}+\lambda_{m}^{*}(t)-\lambda_{m}^{*}(t+1)\right] \\
& \quad \times\left[I_{m}(t)-I_{m}^{*}(t)\right] \\
& +\sum_{t=1}^{T} \sum_{m=1}^{M}\left[\sum_{s=1}^{S} q_{s m}^{r *}(t)-q_{m}^{r *}(t)\right] \times\left[\gamma_{m}(t)-\gamma_{m}^{*}(t)\right] \\
& +\sum_{t=1}^{T} \sum_{m=1}^{M}\left[I_{m}^{*}(t-1)+\beta_{r} q_{m}^{r *}(t)-I_{m}^{*}(t)-\sum_{n=1}^{N} q_{m n}^{*}(t)\right] \\
& \quad \times\left[\lambda_{m}(t)-\lambda_{m}^{*}(t)\right] \geq 0 \\
& \quad \forall\left(q^{r}, Q^{1}, Q^{2}, I, \gamma, \lambda\right) \in \Omega^{M},
\end{aligned}
$$

where $\Omega^{M}=R_{+}^{M T+S M T+M N T+2 M T} \times R^{M T}$.

From the third term of (9), the transaction price can be written as when the network is in equilibrium:

$$
\rho_{m n}^{*}(t)=\frac{\partial c_{m n}^{*}(t)}{\partial q_{m n}(t)}+\lambda_{m}^{*}(t)+\phi_{m n} I_{A}^{m n}(t)
$$

From the 2nd term of (9), in the equilibrium state, we get $\rho_{s m}^{*}(t)=\gamma_{m}^{*}(t)$; then from the 1st term, we get $\lambda_{m}^{*}(t)=$ 
$\left(1 / \beta_{r}\right)\left[\partial f_{m}^{M *}(t) / \partial q_{m}^{r}(t)+\gamma_{m}^{*}(t)\right]=\left(1 / \beta_{r}\right)\left[\partial f_{m}^{M *}(t) / \partial q_{m}^{r}(t)+\right.$ $\rho_{s m}^{*}(t)$. Equation (10) shows that in the equilibrium state, the transaction price between manufacturers and retailers is equal to the sum of marginal transaction cost between manufacturers and retailers, the Lagrange multiplier corresponding to constraint (7), and the advertisement investment amount shared by manufacturer $m$.

4.3. The Optimal Behavior and Equilibrium Condition of Retailers. The retailers need to decide to purchase how many products from manufacturers and sell to consumers in corresponding demand markets in a certain price.

Due to $\widehat{d}_{n}\left(I_{A}^{m n}(t), \rho_{n}(t)\right)$ denoting the random demand of retailer outlet $n$, the demand depends on the advertising investment and the trade price; it is obvious that the more advertising investment paid by manufacturers and retailers is, the larger consumer demand is, whereas the increase of price charged by retailers will lower the product demand. For a given product transaction price $\rho_{n}(t)$ at period $t$, according to the notations illustrated in Table $3, \Phi_{n}\left(x ; \rho_{n}(t)\right)=$ $\int_{0}^{x} \phi_{n}\left(x ; \rho_{n}(t)\right) d x$. Let $s_{n}(t)$ denote the wholesale amount from manufacturers and $s_{n}(t)=\sum_{m=1}^{M} q_{m n}(t)$; group all $s_{n}(t)$ in period $t$ into a column vector $s(t) \in R_{+}^{N}$, and group all $s_{n}(t)$ into a column vector $s_{n} \in R_{+}^{N T}$. In order to express the competition among retailers, we assume that the exhibition function and disposal cost function at retailer $n c_{n}(t)=$ $c_{n}(s(t))$ are related with all retailers.

For retailer $n$, if given $s_{n}(t)$, it is similar as in Dong et al. [5] and Nagurney et al. [4], the expected sales quantity, expected shortage quantity, and expected exceed quantity can be expressed as

$$
\begin{aligned}
& S_{n}\left(s_{n}(t), I_{A}^{m n}(t), \rho_{n}(t)\right) \\
&=E\left[\min \left\{\widehat{d}_{n}\left(I_{A}^{m n}(t), \rho_{n}(t)\right), s_{n}(t)\right\}\right] \\
&=s_{n}(t)-\int_{0}^{s_{n}(t)}\left(s_{n}(t)-x\right) \mathrm{d} \Phi_{n} \\
& \times\left(x, I_{A}^{m n}(t), \rho_{n}(t)\right), \\
& H_{n}\left(s_{n}(t), I_{A}^{m n}(t), \rho_{n}(t)\right) E\left[\max \left\{0, s_{n}(t)-\widehat{d}_{n}\left(I_{A}^{m n}(t), \rho_{n}(t)\right)\right\}\right] \\
&= \int_{0}^{s_{n}}\left(s_{n}-x\right) \mathrm{d} \Phi_{n}\left(x, I_{A}^{m n}(t), \rho_{n}(t)\right), \\
& Q_{n}\left(s_{n}(t), I_{A}^{m n}(t), \rho_{n}(t)\right) \\
&=E\left[\max \left\{0, \hat{d}_{n}\left(I_{A}^{m n}(t), \rho_{n}(t)\right)-s_{n}(t)\right\}\right] \\
&=\int_{s_{n}(t)}^{+\infty}\left(x-s_{n}(t)\right) \mathrm{d} \Phi_{j}\left(x, I_{A}^{m n}(t), \rho_{n}(t)\right) .
\end{aligned}
$$

From (10), we can easily obtain

$$
\begin{aligned}
& \frac{\partial S_{n}\left(s_{n}(t), I_{A}^{m n}(t), \rho_{n}(t)\right)}{\partial s_{n}(t)}=1-\Phi_{n}\left(s_{n}(t), I_{A}^{m n}(t), \rho_{n}(t)\right), \\
& \frac{\partial H_{n}\left(s_{n}(t), I_{A}^{m n}(t), \rho_{n}(t)\right)}{\partial s_{n}(t)}=\Phi_{n}\left(s_{n}(t), I_{A}^{m n}(t), \rho_{n}(t)\right), \\
& \frac{\partial Q_{n}\left(s_{n}(t), I_{A}^{m n}(t), \rho_{n}(t)\right)}{\partial s_{n}(t)}=\Phi_{n}\left(s_{n}(t), I_{A}^{m n}(t), \rho_{n}(t)\right)-1 .
\end{aligned}
$$

For retailer $n$, the maximum expected profit model can be expressed as

$$
\begin{aligned}
& \pi_{n}=\max \left\{\sum_{t=1}^{T} \rho_{n}(t) S_{n}\left(s_{n}(t), I_{A}^{m n}(t), \rho_{n}(t)\right)\right. \\
&-\lambda_{n}^{+} \sum_{t=1}^{T} H_{n}\left(s_{n}(t), I_{A}^{m n}(t), \rho_{n}(t)\right) \\
&-\lambda_{n}^{-} \sum_{t=1}^{T} Q_{n}\left(s_{n}(t), I_{A}^{m n}(t), \rho_{n}(t)\right) \\
&-\sum_{t=1}^{T} c_{n}(s(t))-\sum_{t=1}^{T} \sum_{m=1}^{M} \rho_{m n}(t) q_{m n}(t)-\left(1-\phi_{m n}\right) \\
&\left.\times \sum_{t=1}^{T} \sum_{m=1}^{M} I_{A}^{m n}(t) q_{m n}(t)\right\}
\end{aligned}
$$

$$
\text { s.t. } \quad s_{n}(t)=\sum_{m=1}^{M} q_{m n}(t) .
$$

Using (11) and (13) can be rewritten as

$$
\begin{aligned}
& \pi_{n}=\max \left\{\sum_{t=1}^{T} \rho_{n}(t) s_{n}(t)-\sum_{t=1}^{T}\left(\rho_{n}(t)+\lambda_{n}^{+}\right)\right. \\
& \times \int_{0}^{s_{n}(t)}\left(s_{n}(t)-x\right) \mathrm{d} \Phi_{n}\left(x, \rho_{n}(t)\right)-\lambda_{n}^{-} \\
& \times \sum_{t=1}^{T} \int_{s_{n}}^{+\infty}\left(x-s_{n}(t)\right) \mathrm{d} \Phi_{n}\left(x, \rho_{n}(t)\right) \\
&-\sum_{t=1}^{T} c_{n}(s(t))-\sum_{t=1}^{T} \sum_{m=1}^{M} \rho_{m n}(t) q_{m n}(t)-\left(1-\phi_{m n}\right) \\
&\left.\times \sum_{t=1}^{T} \sum_{m=1}^{M} I_{A}^{m n}(t) q_{m n}(t)\right\}
\end{aligned}
$$

All retailers compete in a noncooperation fashion; using (12), their equilibrium conditions can be described as a 
variational inequality, determining $\left(s_{n}^{*}, Q^{2 *}, \theta^{*}\right) \in \Omega^{N}$, such that

$$
\begin{aligned}
& \sum_{t=1}^{T} \sum_{n=1}^{N}\left[\left(\rho_{n}^{*}(t)+\lambda_{n}^{+}+\lambda_{n}^{-}\right) \Phi_{n}\left(s_{n}^{*}(t), \rho_{n}^{*}(t)\right)\right. \\
& \left.-\rho_{n}^{*}(t)-\lambda_{n}^{-}+\frac{\partial c_{n}\left(s^{*}(t)\right)}{\partial s_{n}(t)}\right] \times\left[s_{n}(t)-s_{n}^{*}(t)\right] \\
& +\sum_{t=1}^{T} \sum_{m=1}^{M} \sum_{n=1}^{N}\left[\left(1-\phi_{m n}\right) I_{A}^{m n}(t)+\rho_{m n}^{*}(t)\right] \\
& \quad \times\left[q_{m n}(t)-q_{m n}^{*}(t)\right] \\
& +\sum_{t=1}^{T} \sum_{n=1}^{N}\left[\sum_{m=1}^{M} q_{m n}^{*}(t)-s_{n}^{*}(t)\right] \times\left[\theta_{n}(t)-\theta_{n}^{*}(t)\right] \geq 0 \\
& \forall\left(s_{n}, Q^{2}, \theta\right) \in \Omega^{N},
\end{aligned}
$$

where $\Omega^{N}=R_{+}^{N T+M N T} \times R^{N T}$.

In (16), $\theta_{n}(t)$ is the Lagrange multiplier corresponding to constraint (14) and $\theta_{n}(t) \in R^{N T}$ is the column vector with the elements of $\theta_{n}(t)$. The transaction price $\rho_{n}^{*}(t)$ is a decision variable which can be obtained from the computing results.

4.4. The Optimal Behavior and Equilibrium Condition of Demand Markets. For the supply chain network, given a fixed advertising investment, the consumers of demand markets buy the products under a price charged by the retailers and it is similar as in Dong et al. [5] and Nagurney et al. [4]

$$
d_{n}\left(I_{A}^{m n}(t), \rho_{n}^{*}(t)\right) \begin{cases}=s_{n}^{*}(t), & \rho_{n}^{*}(t)>0 \\ <s_{n}^{*}(t), & \rho_{n}^{*}(t)=0 .\end{cases}
$$

The consumers' optimal behaviors and equilibrium conditions can be described as a variational inequality, determining $\rho_{n}^{*}(t) \in \Omega^{K}$, such that

$$
\begin{array}{r}
{\left[s_{n}^{*}(t)-d_{n}\left(I_{A}^{m n}(t), \rho_{n}^{*}(t)\right)\right] \times\left[\rho_{n}(t)-\rho_{n}^{*}(t)\right] \geq 0} \\
\forall \rho_{n}(t) \in \Omega^{K},
\end{array}
$$

where $\Omega^{K}=R_{+}^{K T}$.

4.5. The Equilibrium Condition of the Supply Chain Network. Each player in the supply chain network selects the optimal strategy in every period and seeks to maximize the profit in the entire planning horizon on the basis of the other players making optimal decisions. Thus, the network will experience a strategy selecting process and carry out Nash equilibrium in the end. In particular, the product transaction amount and price between the adjacent tires must be equal to that the players want to purchase or sell at every period, and the manufacturers and retailers also need to make decisions about the advertising investment to enhance the expected sales to maximize their profits. So, the whole network equilibrium condition is the sum of (4), (9), (15), and (18). We sum up these equations and obtain the following theorem.
Theorem 1. A strategy pattern $\left(q_{1}^{r *}, q^{r *}, Q^{1 *}, Q^{2 *}, I^{*}, s^{*}, \rho^{*}\right.$, $\left.\eta_{s}^{*}, \gamma^{*}, \lambda^{*}\right) \in \Omega$ of the discrete dynamic supply chain network can be called an equilibrium pattern if and only if it satisfies the following inequality, determining $\left(q_{1}^{r *}, q^{r *}\right.$, $\left.Q^{1 *}, Q^{2 *}, I^{*}, s_{n}^{*}, \rho^{*}, \eta_{s}^{*}, \gamma^{*}, \lambda^{*}, \theta^{*}\right) \in \Omega$, such that

$$
\begin{aligned}
& \sum_{t=1}^{T} \sum_{s=1}^{S}\left[\frac{\partial f_{s}^{r}\left(q_{s}^{r *}(t)\right)}{\partial q_{s}^{r}(t)}-\eta_{s}^{*}(t)\right] \times\left[q_{s}^{r}(t)-q_{s}^{r *}(t)\right] \\
& +\sum_{t=1}^{T} \sum_{m=1}^{M}\left[\frac{\partial f_{m}^{M *}(t)}{\partial q_{m}^{r}(t)}-\beta_{r} \lambda_{m}^{*}(t)+\gamma_{m}^{*}(t)\right] \\
& \times\left[q_{m}^{r}(t)-q_{m}^{r *}(t)\right] \\
& +\sum_{t=1}^{T} \sum_{s=1}^{S} \sum_{m=1}^{M}\left[\frac{\partial c_{s m}^{r *}(t)}{\partial q_{s m}^{r}(t)}+\eta_{s}^{*}(t)-\gamma_{m}^{*}(t)\right] \\
& \times\left[q_{s m}^{r}(t)-q_{s m}^{r *}(t)\right] \\
& +\sum_{t=1}^{T} \sum_{m=1}^{M} \sum_{n=1}^{N}\left[\frac{\partial c_{m n}^{*}(t)}{\partial q_{m n}(t)}+\lambda_{m}^{*}(t)\right. \\
& \left.-\theta_{n}^{*}(t)+I_{A}^{m n *}(t)\right] \\
& \times\left[q_{m n}(t)-q_{m n}^{*}(t)\right] \\
& +\sum_{t=1}^{T} \sum_{m=1}^{M}\left[\frac{\partial H_{m}^{*}(t)}{\partial I_{m}(t)}+\lambda_{m}^{*}(t)-\lambda_{m}^{*}(t+1)\right] \\
& \times\left[I_{m}(t)-I_{m}^{*}(t)\right] \\
& +\sum_{t=1}^{T} \sum_{n=1}^{N}\left[\left(\rho_{n}^{*}(t)+\lambda_{n}^{+}+\lambda_{n}^{-}\right) \Phi_{n}\left(s_{n}^{*}(t), \rho_{n}^{*}(t)\right)\right. \\
& \left.-\rho_{n}^{*}(t)-\lambda_{n}^{-}+\theta_{n}^{*}(t)+\frac{\partial c_{n}\left(s^{*}(t)\right)}{\partial s_{n}(t)}\right] \\
& \times\left[s_{n}(t)-s_{n}^{*}(t)\right] \\
& +\left[s_{n}^{*}(t)-d_{n}\left(I_{A}^{m n *}(t), \rho_{n}^{*}(t)\right)\right] \\
& \times\left[\rho_{n}(t)-\rho_{n}^{*}(t)\right] \\
& +\sum_{t=1}^{T} \sum_{s=1}^{S}\left[q_{s}^{r *}(t)-\sum_{m=1}^{M} q_{s m}^{r *}(t)\right] \\
& \times\left[\eta_{s}(t)-\eta_{s}^{*}(t)\right] \\
& +\sum_{t=1}^{T} \sum_{m=1}^{M}\left[\sum_{s=1}^{S} q_{s m}^{r *}(t)-q_{m}^{r *}(t)\right] \times\left[\gamma_{m}(t)-\gamma_{m}^{*}(t)\right] \\
& +\sum_{t=1}^{T} \sum_{m=1}^{M}\left[I_{m}^{*}(t-1)+\beta_{r} q_{m}^{r *}(t)\right. \\
& \left.-I_{m}^{*}(t)-\sum_{n=1}^{N} q_{m n}^{*}(t)\right]
\end{aligned}
$$




$$
\begin{array}{r}
\times\left[\lambda_{m}(t)-\lambda_{m}^{*}(t)\right] \\
+\sum_{t=1}^{T} \sum_{n=1}^{N}\left[\sum_{m=1}^{M} q_{m n}^{*}(t)-s_{n}^{*}(t)\right] \times\left[\theta_{n}(t)-\theta_{n}^{*}(t)\right] \geq 0 \\
\forall\left(q_{1}^{r}, q^{r}, Q^{1}, Q^{2}, I, s, \rho, \eta_{s}, \gamma, \lambda, \theta\right) \in \Omega \\
+\sum_{t=1}^{T} \sum_{n=1}^{N}\left[\sum_{m=1}^{M} q_{m n}^{*}(t)-s_{n}^{*}(t)\right] \times\left[\theta_{n}(t)-\theta_{n}^{*}(t)\right] \geq 0 \\
\forall\left(q_{1}^{r}, q^{r}, Q^{1}, Q^{2}, I, s_{n}, \rho, \eta_{s}, \gamma, \lambda, \theta\right) \in \Omega,
\end{array}
$$

where $\Omega=\Omega^{S} \times \Omega^{M} \times \Omega^{N} \times \Omega^{K}$.

Proof. Let us sum up (4), (9), (15), and (18); we get the total inequality, determining $\left(q_{1}^{r *}, q^{r *}, Q^{1 *}, Q^{2 *}, I^{*}, s_{n}^{*}\right.$, $\left.\rho^{*}, \eta_{s}^{*}, \gamma^{*}, \lambda^{*}, \theta^{*}\right) \in \Omega$, such that

$$
\begin{aligned}
& \sum_{t=1}^{T} \sum_{s=1}^{S}\left[\frac{\partial f_{s}^{r}\left(q_{s}^{r *}(t)\right)}{\partial q_{s}^{r}(t)}-\eta_{s}^{*}(t)\right] \\
& \times\left[q_{s}^{r}(t)-q_{s}^{r *}(t)\right] \\
& +\sum_{t=1}^{T} \sum_{m=1}^{M}\left[\frac{\partial f_{m}^{M *}(t)}{\partial q_{m}^{r}(t)}-\beta_{r} \lambda_{m}^{*}(t)+\gamma_{m}^{*}(t)\right] \\
& \times\left[q_{m}^{r}(t)-q_{m}^{r *}(t)\right] \\
& +\sum_{t=1}^{T} \sum_{s=1}^{S} \sum_{m=1}^{M}\left[\frac{\partial c_{s m}^{r *}(t)}{\partial q_{s m}^{r}(t)}+\eta_{s}^{*}(t)-\gamma_{m}^{*}(t)\right. \\
& +\sum_{t=1}^{T} \sum_{m=1}^{M}\left[\frac{\partial H_{m}^{*}(t)}{\partial I_{m}(t)}+\lambda_{m}^{*}(t)-\lambda_{m}^{*}(t+1)\right] \\
& \left.+\rho_{s m}^{*}(t)-\rho_{s m}^{*}(t)\right] \\
& +\sum_{t=1}^{T} \sum_{m=1}^{M} \sum_{n=1}^{N}\left[\frac{\partial c_{m n}^{*}(t)}{\partial q_{m n}(t)}+\lambda_{m}^{*}(t)-\theta_{n}^{*}(t)\right. \\
& +\left(1-\rho_{m}^{*}(t)\right]
\end{aligned}
$$

$$
\begin{aligned}
& +\sum_{t=1}^{T} \sum_{n=1}^{N}\left[\left(\rho_{n}^{*}(t)+\lambda_{n}^{+}+\lambda_{n}^{-}\right) \Phi_{n}\left(s_{n}^{*}(t), \rho_{n}^{*}(t)\right)\right. \\
& \left.-\rho_{n}^{*}(t)-\lambda_{n}^{-}+\theta_{n}^{*}(t)+\frac{\partial c_{n}\left(s^{*}(t)\right)}{\partial s_{n}(t)}\right] \\
& \times\left[s_{n}(t)-s_{n}^{*}(t)\right] \\
& +\left[s_{n}^{*}(t)-d_{n}\left(I_{A}^{m n *}(t), \rho_{n}^{*}(t)\right)\right] \\
& \times\left[\rho_{n}(t)-\rho_{n}^{*}(t)\right] \\
& +\sum_{t=1}^{T} \sum_{s=1}^{S}\left[q_{s}^{r *}(t)-\sum_{m=1}^{M} q_{s m}^{r *}(t)\right] \\
& \times\left[\eta_{s}(t)-\eta_{s}^{*}(t)\right] \\
& +\sum_{t=1}^{T} \sum_{m=1}^{M}\left[\sum_{s=1}^{S} q_{s m}^{r *}(t)-q_{m}^{r *}(t)\right] \\
& \times\left[\gamma_{m}(t)-\gamma_{m}^{*}(t)\right] \\
& +\sum_{t=1}^{T} \sum_{m=1}^{M}\left[I_{m}^{*}(t-1)+\beta_{r} q_{m}^{r *}(t)\right. \\
& \left.-I_{m}^{*}(t)-\sum_{n=1}^{N} q_{m n}^{*}(t)\right] \\
& \times\left[\lambda_{m}(t)-\lambda_{m}^{*}(t)\right] \\
& +\sum_{t=1}^{T} \sum_{n=1}^{N}\left[\sum_{m=1}^{M} q_{m n}^{*}(t)-s_{n}^{*}(t)\right] \times\left[\theta_{n}(t)-\theta_{n}^{*}(t)\right] \geq 0 \\
& \forall\left(q_{1}^{r}, q^{r}, Q^{1}, Q^{2}, I, s_{n}, \rho, \eta_{s}, \gamma, \lambda, \theta\right) \in \Omega .
\end{aligned}
$$

We simplify the 3rd and 4th terms in (20) and obtain (19). From (19), we note that the share ratio of advertising investment between manufacturers and retailers does not impact the network equilibrium results; therefore, determining the share ratio will be up to the power of two kinds of players in their bargain.

\section{Numerical Examples}

In this section, we will provide some numerical examples to illustrate the efficiency of the previous equilibrium model and analyze the relevant parameters. To solve the model, there are several algorithms to choose, such as logarithmicquadratic proximal prediction-correction method [33], modified contraction project method [34], smoothing Newton algorithm [35], and others, to name a few. In this paper, we employ the modified contraction project method to solve the variational inequality (19) for its simple steps and obtain the decision variables and Lagrange multiplexer simultaneously. Set the related parameters as follows: the initial value of decision variables and Lagrange multipliers is set to 1 and 
TABLE 5: Cost functions for computational study.

\begin{tabular}{ll}
\hline Notation & Definition \\
\hline$f_{s}\left(q_{1}^{r}(t)\right)=t q_{s}^{r}(t)^{2}+q_{s}^{r}(t)+1$ & Cost function of producing raw materials for supplier $s$ at period $t$ \\
$c_{s m}(t)=q_{s m}(t)^{2}+1.5 q_{s m}(t)+1$ & Transaction cost function undertaken by supplier $s$ related to supply chain $s m$ at period $t$ \\
$f_{m}^{M}(t)=t\left(\beta_{r} q_{m}^{r}(t)\right)^{2}+3 \beta_{r} q_{m}^{r}(t)+2$ & Production cost function for manufacturer $m$ at period $t$ \\
$H_{m}(t)=t I_{m}(t)$ & Inventory cost for manufacturer $m$ at period $t$ \\
$c_{m n}(t)=5.5 q_{m n}(t)^{2}+3 q_{m n}(t)+2$ & Transaction cost function undertaken by manufacturer $m$ related to supply chain $m n$ at period $t$ \\
$c_{n}(t)=0.25\left(\sum_{m=1}^{2} q_{m n}(t)\right)$ & Disposal costs at retailer $n$ at period $t$ \\
\hline
\end{tabular}

TABLE 6: Equilibrium results with delay effect of advertising investment.

\begin{tabular}{|c|c|c|c|c|c|c|}
\hline $\begin{array}{l}\text { Variables } \\
t=1,2,3\end{array}$ & $\begin{array}{c}I_{A}^{m n}(1)=0.15 \\
I_{A}^{m n}(2)=0 \\
I_{A}^{m n}(3)=0\end{array}$ & $\begin{array}{c}I_{A}^{m n}(1)=0 \\
I_{A}^{m n}(2)=0.15 \\
I_{A}^{m n}(3)=0\end{array}$ & $\begin{array}{c}I_{A}^{m n}(1)=0 \\
I_{A}^{m n}(2)=0 \\
I_{A}^{m n}(3)=0.15\end{array}$ & $\begin{array}{c}I_{A}^{m n}(1)=0.15 \\
I_{A}^{m n}(2)=0.15 \\
I_{A}^{m n}(3)=0\end{array}$ & $\begin{array}{c}I_{A}^{m n}(1)=0 \\
I_{A}^{m n}(2)=0.15 \\
I_{A}^{m n}(3)=0.15\end{array}$ & $\begin{array}{l}I_{A}^{m n}(1)=0.15 \\
I_{A}^{m n}(2)=0.15 \\
I_{A}^{m n}(3)=0.15\end{array}$ \\
\hline \multirow{3}{*}{$\begin{array}{l}q_{s m}^{r}(t) \\
s=1,2 \\
m=1,2\end{array}$} & 0.7282 & 0.7259 & 0.7214 & 0.7407 & 0.7340 & 0.7488 \\
\hline & 0.4443 & 0.4431 & 0.4408 & 0.451 & 0.4474 & 0.4552 \\
\hline & 0.3821 & 0.3813 & 0.3797 & 0.3867 & 0.3842 & 0.3896 \\
\hline \multirow{3}{*}{$\begin{array}{l}q_{s}^{r}(t), q_{m}^{r}(t) \\
s=1,2 \\
m=1,2\end{array}$} & 1.4563 & 1.4519 & 1.4429 & 1.4814 & 1.4679 & 1.4976 \\
\hline & 0.8886 & 0.8863 & 0.8815 & 0.9019 & 0.8948 & 0.9105 \\
\hline & 0.7643 & 0.7627 & 0.7594 & 0.7733 & 0.7685 & 0.7791 \\
\hline \multirow{3}{*}{$\begin{array}{l}q_{m n}(t) \\
m=1,2 \\
n=1,2\end{array}$} & 0.5357 & 0.5174 & 0.5182 & 0.5336 & 0.5161 & 0.5322 \\
\hline & 0.5228 & 0.5313 & 0.5132 & 0.5399 & 0.5300 & 0.5386 \\
\hline & 0.4961 & 0.5017 & 0.5106 & 0.5048 & 0.5195 & 0.5228 \\
\hline \multirow{3}{*}{$\begin{array}{l}I_{m}(t) \\
m=1,2\end{array}$} & 0.3849 & 0.4170 & 0.4066 & 0.4142 & 0.4358 & 0.4331 \\
\hline & 0.2280 & 0.2407 & 0.2617 & 0.2364 & 0.2706 & 0.2664 \\
\hline & 0 & 0 & 0 & 0 & 0 & 0 \\
\hline$\pi_{s}$ & 3.3263 & 3.2928 & 3.2254 & 3.5170 & 3.4143 & 3.6415 \\
\hline$\pi_{m}$ & 14.3234 & 14.2429 & 14.0845 & 14.7572 & 14.5163 & 15.0348 \\
\hline$\pi_{n}$ & 27.2004 & 27.0716 & 26.7721 & 28.1674 & 27.7355 & 28.8402 \\
\hline
\end{tabular}

the convergence criterion, for example, the absolute value of difference of decision variables and Lagrange multipliers between two steps is lower than or equal to $10^{-8}$. We assume $\phi_{m n}=0.4, \beta_{r}=1, \lambda_{n}^{-}=1, \lambda_{n}^{+}=1, I_{A}^{m n}(t)=0.15, f_{t}^{t}=0.2$, $f_{t}^{t+1}=0.1$, and $f_{t}^{t+2}=0.05$. The related cost functions and parameters are set as listed in Table 5. It is assumed that the random demands follow uniform distribution in, $d_{k}\left(\rho_{k}(t), I_{A}^{m n}(t)\right) \sim\left[0, b_{k}(t) / \rho_{k}(t)\right], b_{k}(1)=90\left(1+I_{A}^{m n}(1)\right)^{f_{1}^{1}}$, $b_{k}(2)=93 \prod_{i=0}^{1}\left(1+I_{A}^{m n}(2-i)\right)^{f_{2-i}^{2}}$, and $b_{k}(3)=96 \prod_{i=0}^{2}(1+$ $\left.I_{A}^{m n}(3-i)\right)^{f_{3-i}^{3}}$, for $k=1,2, m=1,2, n=1,2$, and $t=1,2,3$.

This paper focuses on the analysis of the following four aspects: (1) the equilibrium results of advertising investment with delay effect and the results listed as in Table 6; (2) the equilibrium results of advertising investment with no delay effect, that is, $f_{t}^{t}=f_{t}^{t+1}=f_{t}^{t+2}=0$, and the results listed as in Table 7; (3) the equilibrium results with one manufacturer advertising investment and the results listed as in Table 8; and (4) the profits of various players with the 1st period advertising investment increasing with/without delay effect, which is illustrated as in Figure 2.
From the first three columns in Table 6, we can find that in the case the advertising delay effect exists, the production volumes, the transaction volumes, and all the players' profits are the highest when the manufacturers and the retailers make advertisements in the 1st period, and then is the 2 nd period, the lowest is the $3 \mathrm{rd}$ period.

From the latter three columns in Table 6 , it can be seen that when advertising is in the 1st and 2 nd periods, all the players' profits are higher than that in the 2 nd and 3 rd periods and lower than that in all the three periods, which implies that the earlier the advertisement is made, the higher profits the players can obtain.

We now turn to analyze the inventory between adjacent periods which describes the characteristic of discrete dynamic supply chain network. The manufacturers can adjust the inventory to maximize the profits in the whole planning horizon. Compare the 1st three columns of Table 6, because of the demand increasing in the 2 nd period as a result of advertising, the inventory transfer from the 1st period to 2 nd period increases; on the other hand, due to the delay effect, the advertising in the 2 nd period also has much influence in 


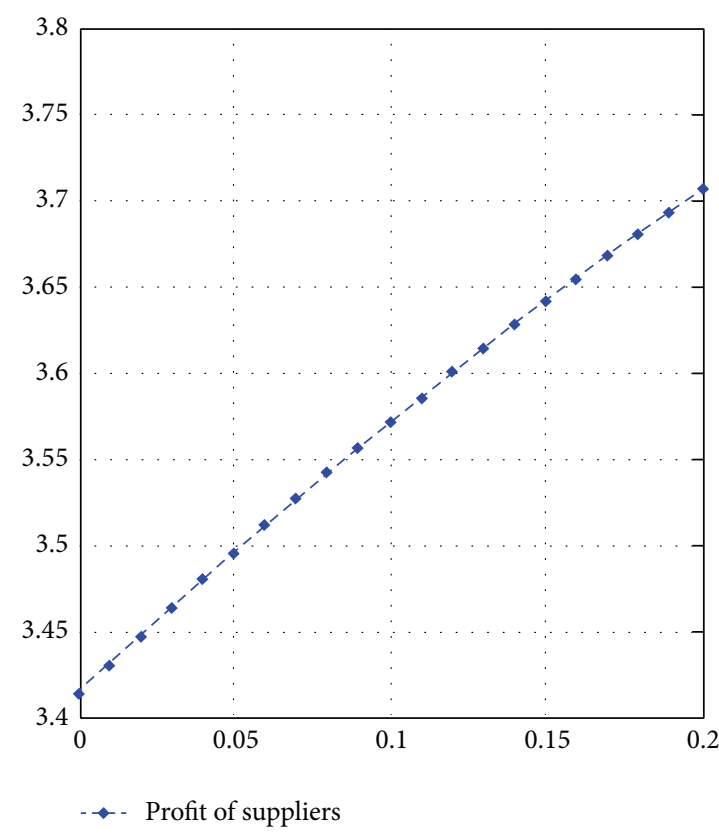

(a)

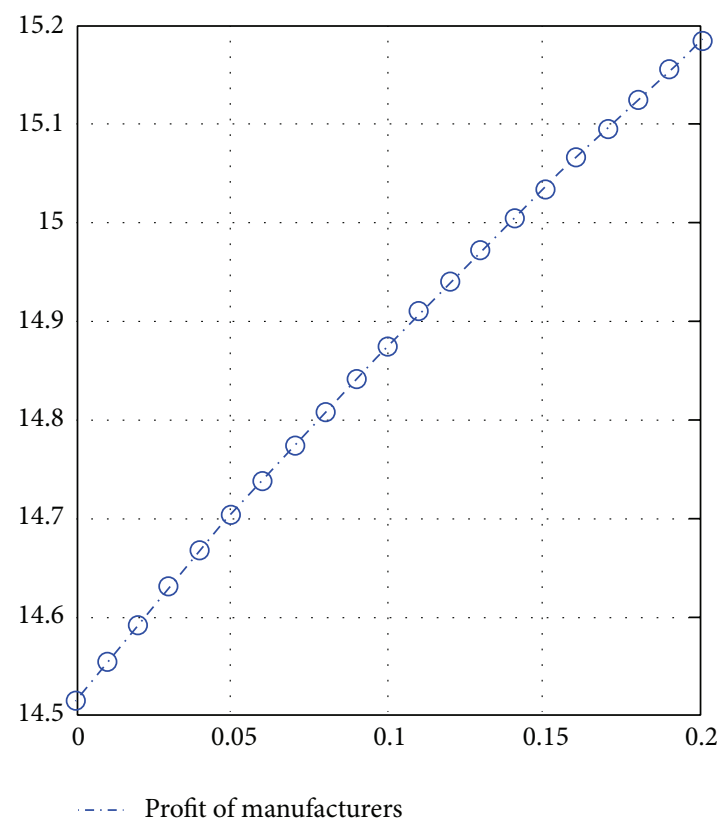

(b)

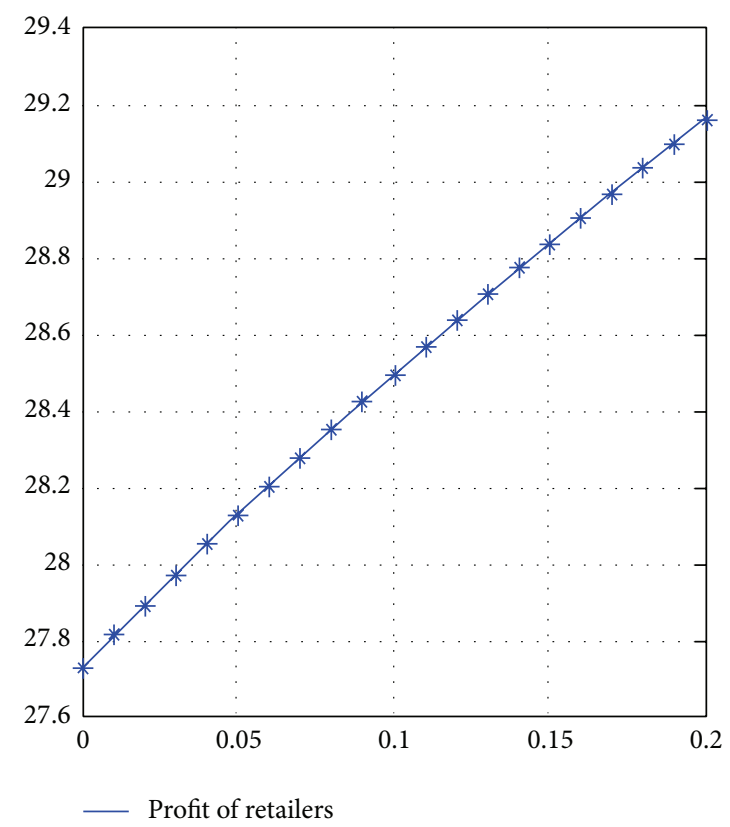

(c)

FIgURE 2: Players' profits in the discrete dynamic supply chain network with delay effect.

the 3 rd period; thus the inventory from the 2 nd period to the $3 \mathrm{rd}$ period also increases. Due to the increasing of the demand in the 3 rd period, the inventory from the 2 nd period to the 3 rd period increases obviously. The latter 3 columns can be analyzed in the same way.

From the latter three columns in Table 7, we can find that, in the absence of delay effect, the manufacturers' profits when making advertisement in all the three periods are lower than that only in the 1 st and 2 nd periods instead. It illustrates that, in some cases, the increased profit through advertisement is less than its investment volume, so at this time, it is meaningless and should not be the manufacturer's optimal strategy. On the other hand, the retailers' profits remain unchanged.

In Table 7 , it is interesting that the volume of $q_{s m}^{r}(t) q_{s}^{r}(t)$ and $q_{m}^{r}(t)$ is almost identical and the profits of all players in these cases are similar too in the first three columns and the 4 th and 5 th, respectively.

Comparing Table 6 with Table 7, we can see that because we only consider three periods, the 3 rd period is the last one; 
TABLE 7: Equilibrium results without delay effect of advertising investment.

\begin{tabular}{|c|c|c|c|c|c|c|}
\hline $\begin{array}{l}\text { Variables } \\
t=1,2,3\end{array}$ & $\begin{array}{c}I_{A}^{m n}(1)=0.15 \\
I_{A}^{m n}(2)=0 \\
I_{A}^{m n}(3)=0\end{array}$ & $\begin{array}{c}I_{A}^{m n}(1)=0 \\
I_{A}^{m n}(2)=0.15 \\
I_{A}^{m n}(3)=0\end{array}$ & $\begin{array}{c}I_{A}^{m n}(1)=0 \\
I_{A}^{m n}(2)=0 \\
I_{A}^{m n}(3)=0.15\end{array}$ & $\begin{array}{c}I_{A}^{m n}(1)=0.15 \\
I_{A}^{m n}(2)=0.15 \\
I_{A}^{m n}(3)=0\end{array}$ & $\begin{array}{c}I_{A}^{m n}(1)=0 \\
I_{A}^{m n}(2)=0.15 \\
I_{A}^{m n}(3)=0.15\end{array}$ & $\begin{array}{l}I_{A}^{m n}(1)=0.15 \\
I_{A}^{m n}(2)=0.15 \\
I_{A}^{m n}(3)=0.15\end{array}$ \\
\hline \multirow{3}{*}{$\begin{array}{l}q_{s m}^{r}(t) \\
s=1,2 \\
m=1,2\end{array}$} & 0.7214 & 0.7215 & 0.7214 & 0.7294 & 0.7294 & 0.7373 \\
\hline & 0.4408 & 0.4408 & 0.4408 & 0.4450 & 0.4450 & 0.4491 \\
\hline & 0.3797 & 0.3797 & 0.3797 & 0.3826 & 0.3826 & 0.3854 \\
\hline \multirow{3}{*}{$\begin{array}{l}q_{s}^{r}(t), q_{m}^{r}(t) \\
s=1,2 \\
m=1,2\end{array}$} & 1.4429 & 1.4430 & 1.4429 & 1.4588 & 1.4588 & 1.4746 \\
\hline & 0.8815 & 0.8816 & 0.8815 & 0.8900 & 0.8900 & 0.8983 \\
\hline & 0.7594 & 0.7595 & 0.7594 & 0.7652 & 0.7652 & 0.7708 \\
\hline \multirow{3}{*}{$\begin{array}{l}q_{m n}(t) \\
m=1,2 \\
n=1,2\end{array}$} & 0.5368 & 0.5182 & 0.5182 & 0.5355 & 0.5168 & 0.5342 \\
\hline & 0.5132 & 0.5320 & 0.5132 & 0.5307 & 0.5307 & 0.5295 \\
\hline & 0.4919 & 0.4919 & 0.5106 & 0.4907 & 0.5094 & 0.5082 \\
\hline \multirow{3}{*}{$\begin{array}{l}I_{m}(t) \\
m=1,2\end{array}$} & 0.3692 & 0.4067 & 0.4066 & 0.3878 & 0.4251 & 0.4062 \\
\hline & 0.2243 & 0.2243 & 0.2617 & 0.2163 & 0.2536 & 0.2456 \\
\hline & 0 & 0 & 0 & 0 & 0 & 0 \\
\hline$\pi_{s}$ & 3.2254 & 3.2263 & 3.2254 & 3.3450 & 3.3450 & 3.4646 \\
\hline$\pi_{m}$ & 14.0953 & 14.0955 & 14.0845 & 14.3703 & 14.3597 & 14.6342 \\
\hline$\pi_{n}$ & 26.7327 & 26.7527 & 26.7721 & 27.3596 & 27.3991 & 28.0059 \\
\hline
\end{tabular}

TABLE 8: Equilibrium results with only advertising investment of manufacturer 1.

\begin{tabular}{|c|c|c|c|c|c|c|}
\hline $\begin{array}{l}\text { Variables } \\
t=1,2,3\end{array}$ & $\begin{array}{c}I_{A}^{1 n}(1)=0.15 \\
I_{A}^{1 n}(2)=0 \\
I_{A}^{1 n}(3)=0\end{array}$ & $\begin{array}{c}I_{A}^{1 n}(1)=0 \\
I_{A}^{1 n}(2)=0.15 \\
I_{A}^{1 n}(3)=0\end{array}$ & $\begin{array}{c}I_{A}^{1 n}(1)=0 \\
I_{A}^{1 n}(2)=0 \\
I_{A}^{1 n}(3)=0.15\end{array}$ & $\begin{array}{c}I_{A}^{1 n}(1)=0.15 \\
I_{A}^{1 n}(2)=0.15 \\
I_{A}^{1 n}(3)=0\end{array}$ & $\begin{array}{c}I_{A}^{1 n}(1)=0 \\
I_{A}^{1 n}(2)=0.15 \\
I_{A}^{1 n}(3)=0.15\end{array}$ & $\begin{array}{l}I_{A}^{1 n}(1)=0.15 \\
I_{A}^{1 n}(2)=0.15 \\
I_{A}^{1 n}(3)=0.15\end{array}$ \\
\hline \multirow{3}{*}{$\begin{array}{l}q_{1 n}(t) \\
n=1,2\end{array}$} & 0.5236 & 0.5207 & 0.5211 & 0.5248 & 0.5222 & 0.5263 \\
\hline & 0.5212 & 0.5189 & 0.5161 & 0.5257 & 0.5205 & 0.5273 \\
\hline & 0.4970 & 0.4999 & 0.4978 & 0.5038 & 0.5048 & 0.5087 \\
\hline \multirow{3}{*}{$I_{1}(t)$} & 0.3955 & 0.4954 & 0.3934 & 0.4064 & 0.4043 & 0.4118 \\
\hline & 0.2345 & 0.2413 & 0.2389 & 0.2435 & 0.2480 & 0.2503 \\
\hline & 0 & 0 & 0 & 0 & 0 & 0 \\
\hline$\pi_{1}$ & 14.0075 & 13.9653 & 13.8845 & 14.1539 & 14.0303 & 14.2186 \\
\hline \multirow{3}{*}{$\begin{array}{l}q_{2 n}(t) \\
n=1,2\end{array}$} & 0.5327 & 0.5161 & 0.5165 & 0.5293 & 0.5131 & 0.5263 \\
\hline & 0.5166 & 0.5280 & 0.5115 & 0.5302 & 0.5250 & 0.5273 \\
\hline & 0.4924 & 0.4954 & 0.5069 & 0.4947 & 0.5093 & 0.5087 \\
\hline \multirow{3}{*}{$I_{2}(t)$} & 0.3773 & 0.4081 & 0.4025 & 0.3973 & 0.4225 & 0.4118 \\
\hline & 0.2255 & 0.2322 & 0.2571 & 0.2253 & 0.2571 & 0.2503 \\
\hline & 0 & 0 & 0 & 0 & 0 & 0 \\
\hline$\pi_{2}$ & 14.1659 & 14.1223 & 14.0353 & 14.4704 & 14.3393 & 14.6873 \\
\hline
\end{tabular}

therefore, the 3rd column in the two Tables has no difference with or without delay effect. When considering delay effect, the transaction volume in the 1st period is lower than that without delay effect except the 3rd column, whereas in the next 2 periods, the former is higher than the latter.

From Table 8, it can be obviously seen that when only manufacturer 1 makes advisements, the quantity of selling products to retailers is higher than that of manufacturer 2 , but his profit is lower; in the same time, the higher the advertising investment of manufacturer 1 is, the bigger the profits of the two manufacturers are, and the bigger the profit difference between the two manufacturers is. Therefore, we can draw a conclusion when multiple firms engage in homogeneous products; one firm's advertising activity also has a positive effect on the other firms, which makes the so-called "Free-Rider Phenomenon" emerge and when the advertising investment is bigger, this phenomenon is more obvious.

Figures 2 and 3 illustrate the impacts of the advertising investment in the first period when the advertising in the next 


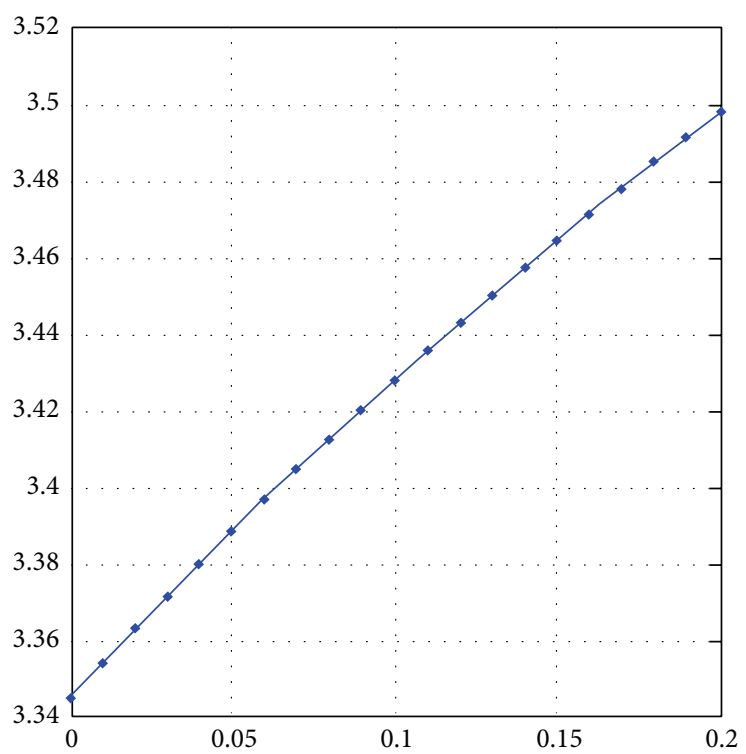

$\rightarrow$ Profit of suppliers

(a)

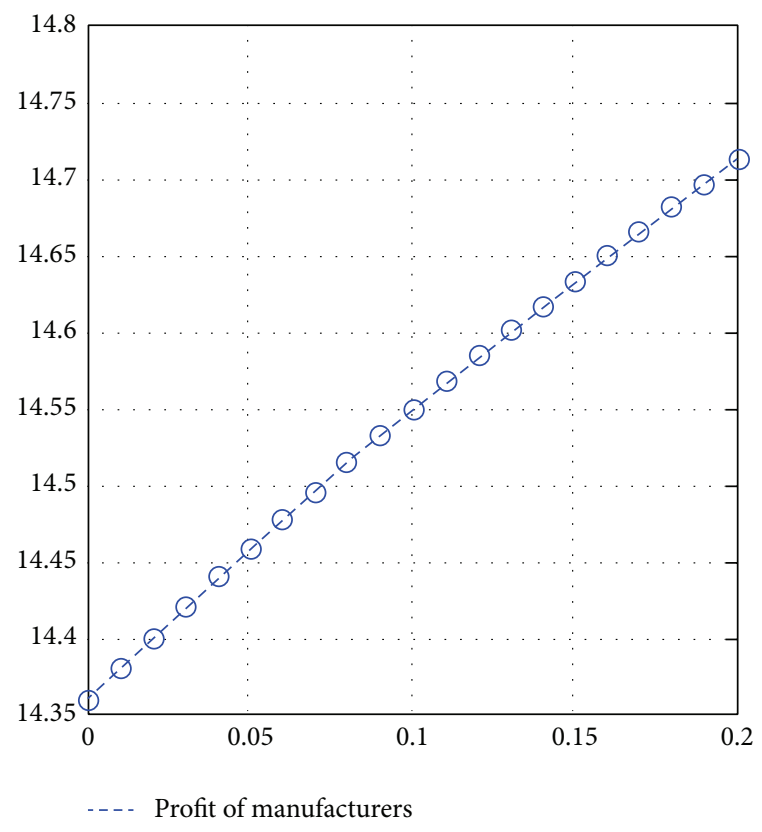

(b)

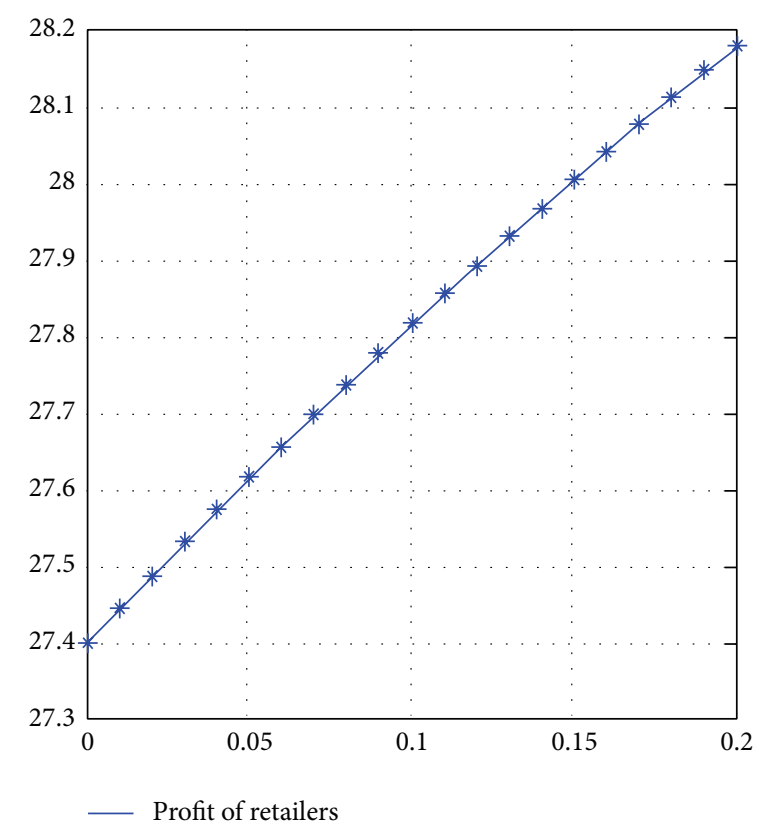

(c)

FIGURE 3: Players' profits in the discrete dynamic supply chain network without delay effect.

2 periods is fixed. The profits of all players in the supply chain network are higher with advertising than that without advertising and increase depending on the advertising investment volume, whereas the increasing margin is smaller and smaller.

From Figures 2 and 3, we also note that the profit differences of all actors are becoming bigger and bigger when the advertising investment in the 1st period increases. For example, when $I_{A}^{m n}(1)=0$, the profit difference of manufacturers is $14.5163-14.360=0.1563$; when $I_{A}^{m n}(1)=0.2$, the profit difference is $14.5163-14.360=0.1563 ; 15.1832-14.7126=$ 0.4706 . The profits of suppliers and retailers can be computed in the same way and have similar trends.

\section{Conclusions}

In the discrete dynamic decision making environment, this paper proposes a supply chain network model with demand uncertainties. The manufacturers purchase the raw 
materials from suppliers and sell products to consumers in demand markets by way of retailers; in the same time, the manufacturers and retailers use the advertising strategy to increase the demand of products, and the advertising investment has delay effect in the next periods. Using variational inequality theory, complement theory, and Lagrange duality theory, we formulate the profit functions and optimal behaviors of various players in the network and in turn compute the equilibrium results by modified projection and contraction algorithm. In the numerical examples, we illustrate the effectiveness of our model and analyze the impact of different advertising strategies on the equilibrium results.

From the numerical examples, we obtain the following conclusions: (1) when considering the delay effects, the earlier the advertising investment is made, the more profits the enterprises can obtain, and the whole supply chain network will benefit from the advertising strategy; (2) when not considering the delay effect, the advertising strategy is not always beneficial for the enterprises; if the investment is higher than the profit resulting from the strategy, the extra investment is harmful to enterprise; (3) if there are only part of the enterprises that make advertising activities, it is likely that the so-called "Free-Rider Phenomenon" emerges; (4) when advertising investment increases, the profit difference will magnify with delay effect than that without the effect. The managerial insights obtained in this paper may give insights to the decision makers in the enterprises and theorists in the supply chain management.

Future research may be in the following directions: as a common policy for promoting products, advertising strategy investment must have the cap constraints because of the limitation of funds.

\section{Conflict of Interests}

The authors declare that there is no conflict of interests regarding the publication of this paper.

\section{Acknowledgments}

This paper is supported by the National Natural Science Foundation, China (nos. 71371102 and 71273149) and International (regional) Cooperation and Exchange, China (no. 71311120090).

\section{References}

[1] M. C. Cooper, M. L. Douglas, and D. P. Janus, "Supply chain management: more than a new name for logistics," International Journal of Logistics Management, vol. 8, no. 1, pp. 1-14, 1997.

[2] M. Christopher, Logistics and Supply Chain Management, Pearson UK, 2012.

[3] B. M. Beamon, "Supply chain design and analysis: models and methods," International Journal of Production Economics, vol. 55, no. 3, pp. 281-294, 1998.

[4] A. Nagurney, J. Dong, and D. Zhang, "A supply chain network equilibrium model," Transportation Research E, vol. 38, no. 5, pp. 281-303, 2002.
[5] J. Dong, D. Zhang, and A. Nagurney, "A supply chain network equilibrium model with random demands," European Journal of Operational Research, vol. 156, no. 1, pp. 194-212, 2004.

[6] H. Sarimveis, P. Patrinos, C. D. Tarantilis, and C. T. Kiranoudis, "Dynamic modeling and control of supply chain systems: a review," Computers and Operations Research, vol. 35, no. 11, pp. 3530-3561, 2008.

[7] J. Yue, J. Austin, Z. Huang, and B. Chen, "Pricing and advertisement in a manufacturer-retailer supply chain," European Journal of Operational Research, vol. 231, no. 2, pp. 492-502, 2013.

[8] A. Nagurney, J. Cruz, J. Dong, and D. Zhang, "Supply chain networks, electronic commerce, and supply side and demand side risk," European Journal of Operational Research, vol. 164, no. 1, pp. 120-142, 2005.

[9] A. Nagurney and F. Toyasaki, "Reverse supply chain management and electronic waste recycling: a multitiered network equilibrium framework for e-cycling," Transportation Research E, vol. 41, no. 1, pp. 1-28, 2005.

[10] K. Wu, A. Nagurney, Z. Liu, and J. K. Stranlund, "Modeling generator power plant portfolios and pollution taxes in electric power supply chain networks: a transportation network equilibrium transformation," Transportation Research D, vol. 11, no. 3, pp. 171-190, 2006.

[11] D. Hammond and P. Beullens, "Closed-loop supply chain network equilibrium under legislation," European Journal of Operational Research, vol. 183, no. 2, pp. 895-908, 2007.

[12] G. Yang, Z. Wang, and X. Li, "The optimization of the closedloop supply chain network," Transportation Research E, vol. 45, no. 1, pp. 16-28, 2009.

[13] A. H. Masoumi, M. Yu, and A. Nagurney, "A supply chain generalized network oligopoly model for pharmaceuticals under brand differentiation and perishability," Transportation Research E, vol. 48, no. 4, pp. 762-780, 2012.

[14] Q. Qiang, K. Ke, T. Anderson, and J. Dong, “The closed-loop supply chain network with competition, distribution channel investment, and uncertainties," Omega, vol. 41, no. 2, pp. 186194, 2013.

[15] M. Yu and A. Nagurney, "Competitive food supply chain networks with application to fresh produce," European Journal of Operational Research, vol. 224, no. 2, pp. 273-282, 2013.

[16] F. Toyasaki, P. Daniele, and T. Wakolbinger, "A variational inequality formulation of equilibrium models for end-of-life products with nonlinear constraints," European Journal of Operational Research, vol. 236, no. 1, pp. 340-350, 2014.

[17] J. M. Cruz and T. Wakolbinger, "Multiperiod effects of corporate social responsibility on supply chain networks, transaction costs, emissions, and risk," International Journal of Production Economics, vol. 116, no. 1, pp. 61-74, 2008.

[18] P. Daniele, "Evolutionary variational inequalities and applications to complex dynamic multi-level models," Transportation Research E, vol. 46, no. 6, pp. 855-880, 2010.

[19] J. M. Cruz and Z. Liu, "Modeling and analysis of the multiperiod effects of social relationship on supply chain networks," European Journal of Operational Research, vol. 214, no. 1, pp. 39-52, 2011.

[20] Y. Hamdouch, "Multi-period supply chain network equilibrium with capacity constraints and purchasing strategies," Transportation Research C, vol. 19, no. 5, pp. 803-820, 2011.

[21] Z. Liu and J. M. Cruz, "Supply chain networks with corporate financial risks and trade credits under economic uncertainty," International Journal of Production Economics, vol. 137, no. 1, pp. 55-67, 2012. 
[22] Z. Feng, Z. Wang, and Y. Chen, "The equilibrium of closed-loop supply chain super network with time-dependent parameters," Transportation Research Part E, vol. 64, pp. 1-11, 2014.

[23] G. Aust and U. Buscher, "Cooperative advertising models in supply chain management: a review," European Journal of Operational Research, vol. 234, no. 1, pp. 1-14, 2014.

[24] M. Bergen and G. John, "Understanding cooperative advertising participation rates in conventional channels," Journal of Marketing Research, vol. 34, no. 3, pp. 357-369, 1997.

[25] M. Lei, S. Sun, and D. Yang, "A study of the joint advertising channels," Journal of Service Science and Management, vol. 2, no. 4, pp. 418-426, 2009.

[26] T. Xiao, X. Yan, and J. Zhao, "Coordination of a supply chain with advertising investment and allowing the second ordering," Technology and Investment, vol. 1, no. 3, pp. 191-200, 2010.

[27] T. Chen, "Coordinating the ordering and advertising policies for a single-period commodity in a two-level supply chain," Computers and Industrial Engineering, vol. 61, no. 4, pp. 12681274, 2011.

[28] X. He, A. Krishnamoorthy, A. Prasad, and S. P. Sethi, "Retail competition and cooperative advertising," Operations Research Letters, vol. 39, no. 1, pp. 11-16, 2011.

[29] Y. Tsao and G. Sheen, "Effects of promotion cost sharing policy with the sales learning curve on supply chain coordination," Computers and Operations Research, vol. 39, no. 8, pp. 18721878, 2012.

[30] S. Jogensen and G. Zaccour, "A survey of game-theoretic models of cooperative advertising," European Journal of Operational Research, vol. 237, no. 1, pp. 1-14, 2014.

[31] W. Zhang, S. Li, D. Zhang, and W. Hou, "On the impact of advertising initiatives in supply chains," European Journal of Operational Research, vol. 234, no. 1, pp. 99-107, 2014.

[32] L. Lambertini, "Coordinating static and dynamic supply chains with advertising through two-part tariffs," Automatica, vol. 50, no. 2, pp. 565-569, 2014.

[33] B. He, Y. Xu, and X. Yuan, "A logarithmic-quadratic proximal prediction-correction method for structured monotone variational inequalities," Computational Optimization and Applications, vol. 35, no. 1, pp. 19-46, 2006.

[34] G. M. Korpelevich, "The extra gradient method for finding saddle points and other problems," Matekon, vol. 13, pp. 35-49, 1977.

[35] L. Zhang and Y. Zhou, "A new approach to supply chain network equilibrium models," Computers \& Operations Research, vol. 63, no. 1, pp. 82-88, 2012. 


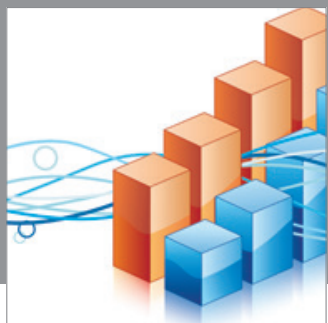

Advances in

Operations Research

mansans

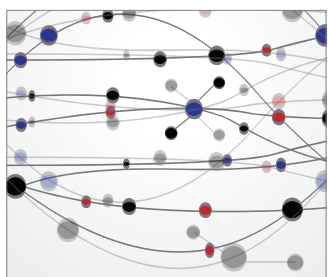

The Scientific World Journal
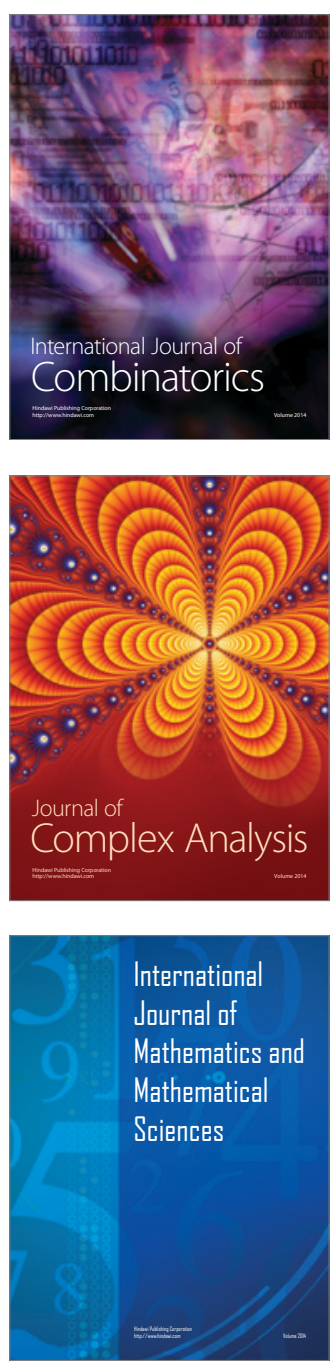
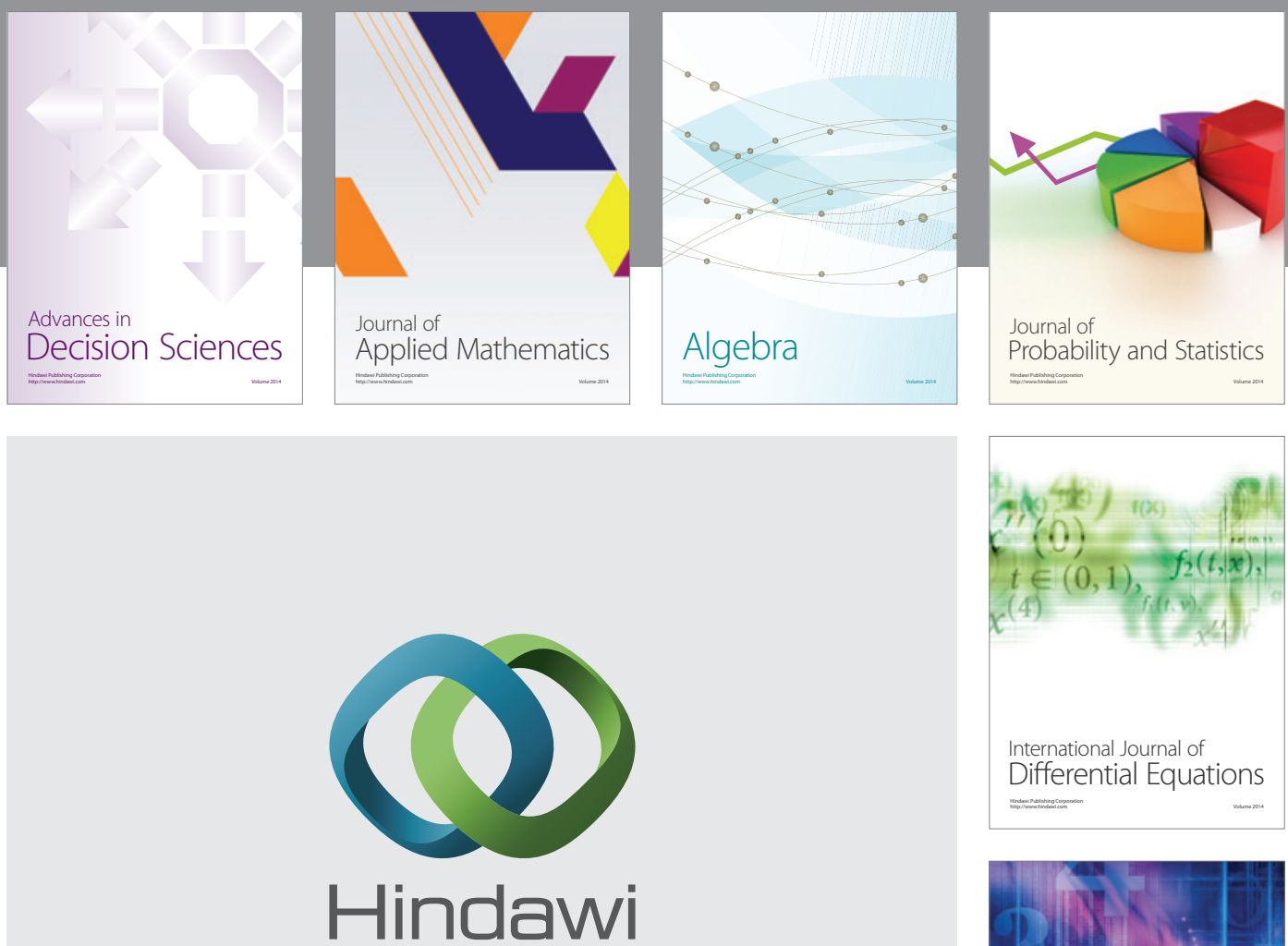

Submit your manuscripts at http://www.hindawi.com
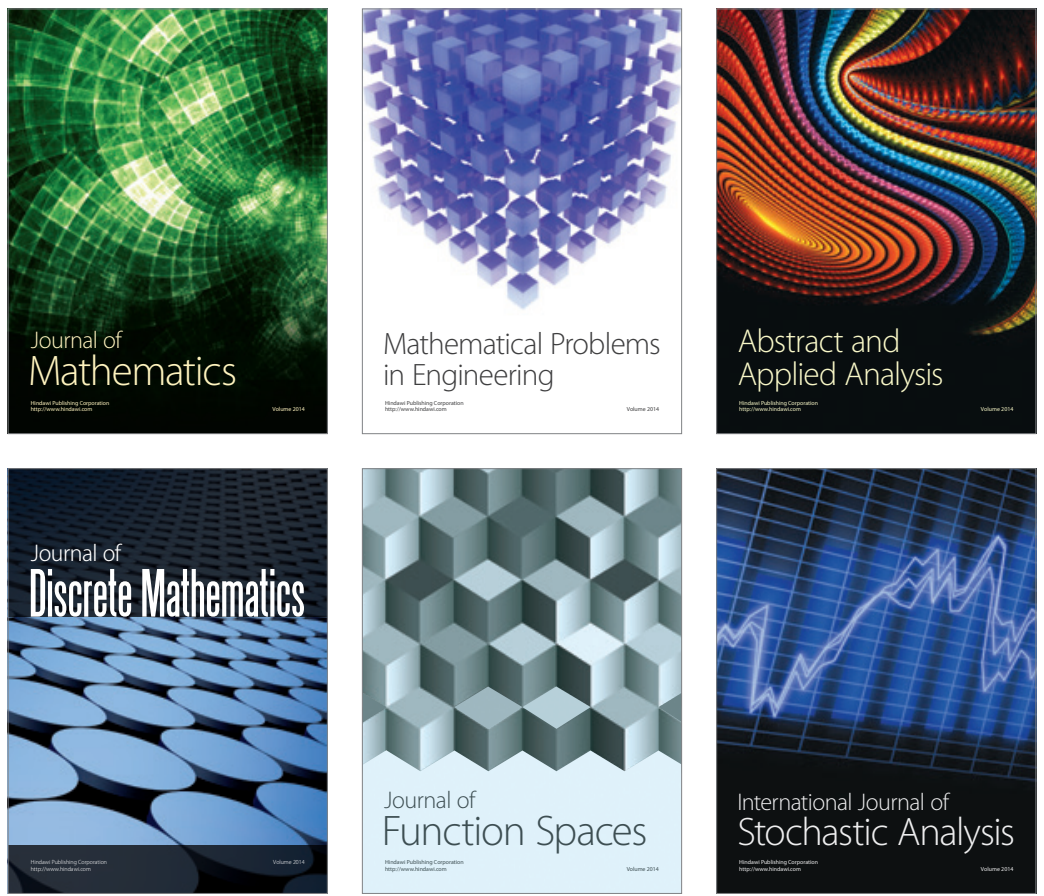

Journal of

Function Spaces

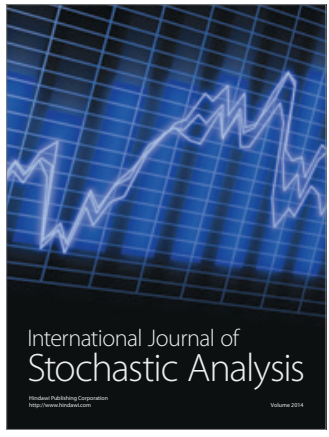

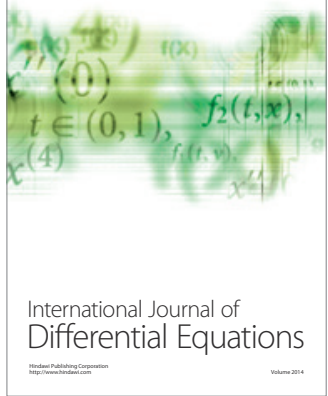
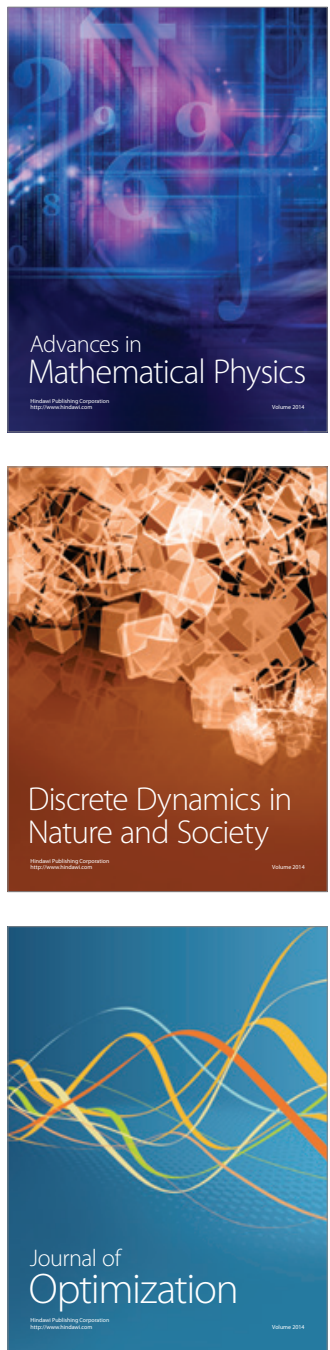